\title{
LIMINALITEIT EN IDENTITEIT IN DE ROMANS VAN TOMMY WIERINGA JOE SPEEDBOOT, CAESARION EN DIT ZIJN DE NAMEN
}

\author{
SONYA DIMITROVA
}

\section{ABSTRACT \\ Liminality and identity in Tommy Wieringa's novels Joe Speedboat, Caesarion and Dit zijn de namen}

Tommy Wieringa (1967) is one of the most prominent contemporary Dutch novelists. His three most famous novels - Joe Speedboat, Caesarion and Dit zijn de namen depict different aspects of liminal identity. Most of the characters cannot successfully accomplish, however, a certain liminal stage. This is due to various reasons which could be analyzed using a psychoanalytic and poststructural approach, for example, the theories of Jacques Lacan, Donald Winnicott, René Girard and Jacques Derrida. The experiences of the characters reflect many of these tendencies and interestingly enough demonstrate a sense of standstill even in the midst of mobility.

Key words: identity; liminality; symbolic order; oedipus complex; scapegoat

\section{Inleiding}

Het onderwerp van mijn dissertatieonderzoek is identiteit en andersheid in de romans Joe Speedboot, Caesarion en Dit zijn de namen van Tommy Wieringa. De vragen waarmee ik me bezighoud zijn onder meer hoe de ontwikkeling van het individu en de maatschappij daar wordt beschreven en welke de auteursstrategieën daarbij zijn. In deze bijdrage analyseer ik de romans aan de hand van de psychoanalyse, de liminaliteit en een theorie over het slachoffermechanisme. Het artikel gaat specifiek in op de liminale identiteit van de hoofdpersonages in Wieringa's romans. De redenen voor de onsuccesvolle liminale overgang oftewel de overwegende stilstand bij een meestal enorme fysieke mobiliteit doorgrond ik vanuit een psychoanalytisch en poststructuralistisch uitgangspunt. Mijns inziens ligt de onbereikbaarheid van de drempel bij een niet te overbruggen traumatische ervaring uit het heden of het verleden van de personages. Ik licht daartoe eerst het begrip liminaliteit toe, vervolgens zet ik enkele ideeën uit de theorieën van Lacan en Winnicott, René Girard en Derrida uiteen en uiteindelijk licht ik mijn bevindingen toe aan de hand van voorbeelden uit de onderzochte romans. 


\section{Het begrip liminaliteit}

"Liminaliteit" betekent letterlijk "grensovergang" of "drempel”. Deze term ontleen ik aan het werk van de etnoloog Arnold van Gennep en de antropoloog Victor Turner. Daarmee bedoelen zij doorslaggevende drempelervaringen zoals onverwachte gebeurtenissen en beslissende omwentelingen, hele levensperiodes of zelfs historische tijdperken. De liminaliteit omvat meer specifiek drie opeenvolgende fasen: afscheiding, drempel en herintrede. Het is echter niet vanzelfsprekend dat deze altijd even soepel worden voltooid. Sterker nog, men kan in één van die fasen blijven vastzitten en niet in staat zijn die af te sluiten. De redenen voor deze stagnatie kunnen nader worden gearticuleerd met behulp van psychoanalytische en poststructuralistische inzichten.

\subsection{Overzicht van de liminale context in de romans}

De hoofdpersonages in Wieringa's romans bevinden zich in een overgangsperiode in hun leven, oftewel in een liminale fase. In Joe Speedboot en Caesarion speelt de adolescentie een centrale rol, de ongetwijfeld essentiële overgang van de kinderjaren naar volwassenheid. Anderzijds evolueert Pontus Beg - de hoofdpersoon in Dit zijn de namen langzaam van volwassenheid naar ouderdom en lijdt hij onder een midlifecrisis. Bij de meeste personages wordt de cruciale overgang echter niet afgerond.

\section{Inzichten van de Franse psychoanalyticus Jacques Lacan}

De Franse psychoanalyticus Jacques Lacan maakt een onderscheid tussen drie dimensies die de menselijke ervaring structureren - het imaginaire, het symbolische en het reële.

\subsection{Intrede in de symbolische orde}

Het kind in de pre-verbale en pre-oedipale fase verkeert in het imaginaire - een wereld vol impressies en fantasieën. Het kind kan nog niet spreken, maar geniet de onmiddelijke bevrediging van zijn wensen, herkent zichzelf nog niet als een apart lichaam en onderkent nog geen grenzen tussen zichzelf en de rest van de wereld met name de moeder. Het einde van deze pre-verbale en pre-oedipale fase komt met de intrede in de symbolische orde en gaat gepaard met tal van onmogelijkheden en onontkoombare verboden. In de symbolische orde is het reële gesymboliseerd en conceptueel geconstrueerd door het representatieve systeem van de taal. Het reële is ongrijpbaar omdat het nooit volledig talig kan worden gerepresenteerd. Met de intrede in het symbolische gaat de staat van imaginaire gelukzalige onmiddellijkheid verloren en moet er rekening met talloze restricties worden gehouden. Zijn hele leven blijft de mens onbewust verlangen naar de volkomen toestand van onvoorwaardelijke totaliteit en alomvattende verbondenheid in het imaginaire. Omdat dit ideaal niet te bereiken is, heeft de mens levenslang te kampen met een constant nijpend gevoel van gebrekkigheid, onvolledigheid en onvolmaaktheid. Om dit ongemak te dempen en het verlangen enigszins te vervullen grijpt hij naar de meest uiteenlopende 
symbolische vervangers zoals fysieke, mentale of emotionele verslavingen. Zelfs liefde is volgens Lacan een vervanger. Ook diverse ideologieën kunnen de mens tot een schijnbaar geheel maken. Het menselijke leven blijkt zo een onophoudelijke zoektocht naar geschikte illusies die eerst als waarheden worden beleefd om later te worden afgekeurd. Zo bijvoorbeeld streven de jongeren uit Joe Speedboot en Caesarion steeds weer naar de een of andere vorm van erkenning, ook in het kader van liefdesrelaties, en Pontus Beg uit Dit zijn de namen gebruikt daarvoor de joodse godsdienst - religie als substituut par excellence.

\subsection{De rol van het spiegelstadium voor de identiteitsvorming en de identiteitswaarneming}

Het spiegelstadium speelt een cruciale rol bij de intrede in het symbolische. Daarbij ziet het kind voor het eerst zijn spiegelbeeld wat eigenlijk een vorm van miskenning is omdat het kind zich identificeert met een beeld van buitenaf. Volgens Lacan hebben wij de erkenning van de anderen nodig om een gevoel van identiteit te ervaren. Hij onderscheidt daarbij tussen de kleine, gelijke ander en de grote Ander - de wet van de symbolische orde. In een ruimere zin staat de grote Ander voor de heersende sociale, culturele en maatschappelijke conventies die beweren het laatste woord te zeggen te hebben over het menselijke leven en gedrag. Onze identiteit is geconstrueerd in een interactie met wat buiten ons is en ons reflecteert. Het is onvermijdelijk dat de externe configuraties voortdurend veranderen. Daarom is identiteit geen stabiel en duidelijk gefixeerd gegeven, eerder een variabele in een proces dat nooit definitief kan worden voltooid. Dat dit proces niet altijd vlekkeloos verloopt is te wijten aan verschillende oorzaken en diverse symptomen, zoals traumatische ervaringen.

\section{Stilstand en het valse zelf}

Eén daarvan is het valse zelf. Deze term is geïntroduceerd door de Engelse psychoanalyticus Donald Winnicott. Deze sociale façade wordt opgebouwd vanwege inbreuken van buitenaf op de intrinsieke talenten en mogelijkheden van het kind, bijvoorbeeld als de zorgende figuren niet goed genoeg zijn. Het kind stemt zich dan af op de maatschappelijke normen of op de noden van andere mensen en verloochent zichzelf. "The False Self has lost what both Heidegger and Lacan describe as the subject's poetic relationship with the world. Such a Self is no longer able to distinguish its desires from what the collective order determines to be desirable" (Krishner 2011: 140). Het subject zit klem in zijn symptoom. Ontwikkeling is niet langer mogelijk vanwege de niet effectieve psychologische patronen.

"A symptom indicates, among other things, that something in the subject's psychic life has become stuck or jammed - that something interferes with the flow of inner energy. Consequently, if the subject falls into self-undermining patterns of predictable behavior - the Freudian repetition compulsion - it is because it is unable to break out of circuits of energy that have over time solidified into stubbornly inflexible patterns. The False Self tends to be caught in its own suffering in the sense that it cannot escape the narrow parameters it has set for its existence." (Krishner 2011: 140) 
Dit uit zich in gevoelens, situaties of belevenissen van beklemmende stilstand en in een ontbrekende of moeizame liminale overgang.

\section{De weerspiegeling van het theoretische kader in de romans}

\subsection{Joe Speedboot - de gevangenis van de kunstmatige identiteit}

In Joe Speedboot selecteer ik drie voorbeelden van personages die niet in staat zijn aan bepaalde psychologische of sociaal-maatschappelijke patronen te ontsnappen.

Joe Speedboot is één van de hoofdpersonages in de gelijknamige roman. Hij is een 16-jarige jongen die met zijn familie belandt in het typisch Nederlandse dorp Lomark waar het verhaal zich afspeelt. Omdat Joe een nieuwkomer is, maakt hij gebruik van de mogelijkheid met zijn identiteit te experimenteren, namelijk zich liegend uit te vinden door zich een nieuwe naam te verzinnen. Zijn echte naam is Achiel Stephaan Ratzinger. Die verklapt hij echter aan niemand, en pas tegen het einde van het verhaal komen zijn vrienden Fransje en PJ achter zijn grote geheim. In het kader van de symbolische orde heeft de naam een cruciale rol bij het identificeren en differentiëren van het subject. Joe kiest voor zichzelf bewust een pseudoniem waar het accent tegelijkertijd ligt op snelheid "speed" en op een voertuig "boot" ligt. Hij wil zo graag een imago van zichzelf creëren dat uitsluitend te maken heeft met beweging, snelheid en rusteloosheid. En vanwege de traditionele opvattingen roept de voornaam Achiel niet per se zulke associaties in de anderen op. "Hij wist dat hij met zijn echte naam nooit zou kunnen worden wat hij wilde zijn” (Wieringa 2005: 25). Zijn echte naam is voor hem een duidelijk teken van zwakte en ontbrekende wilskracht, dus een soort vervloeking waar hij zich machteloos tegenover voelt. Dat dit al van zijn geboorte af bepaald gegeven een niet te overbruggen symptoom voor hem is, blijkt eerst uit zijn hardnekkige beslotenheid deze geheim te houden. Dat gaat vervolgens gepaard met zijn obsessie voor mobiliteit en mechanica wat tot een onwil leidt om de adolescentie eindelijk te verlaten en een volwassen man te worden. In plaats van die waarheid toe te geven, blijft hij zijn kunstmatige identiteit koesteren. Hij kan de drempel niet over, effectief verder naar een volgende levensfase doorgaan en zit vreemd genoeg klem in een cirkel van onophoudelijke, niet doelgerichte beweging.

Een andere nieuwkomer in Lomark is PJ. De indrukwekkende Zuid-Afrikaanse schoonheid verhuist met haar familie naar het dorp van Joe en Fransje. Eerder in Kaapstad was zij een redelijk mollig meisje. Zij kreeg toen toevallig een opmerking van haar moeder dat een dikke jongen een geschikte partner voor haar zou kunnen zijn. Dit raakt haar enorm en zij doet veel moeite om een nieuw uiterst vrouwelijk en aantrekkelijk imago van haarzelf te creëren. Als gevolg daarvan ontwikkelt zij een eetstoornis. Zij lijdt namelijk aan bulimia neurosa. "Voor vrouwen die aan boulimie lijden, is de wereld een verwrongen spiegel waarin ze voortdurend proberen het juiste pose aan te nemen" (Wieringa 2005: 269). Bovendien deelt ze het bed met heel wat partners en wordt zij door één van hen zelfs "hoer van de eeuw" en "een volmaakt prachtig, gewetenloos monster" genoemd. Zij kan niet aan de noodzak ontkomen om steeds weer haar slanke en sexy 
lichaam in de ogen van iemand anders te zien bevestigd worden; zij is verslaafd aan de erkenning en bewondering van verschillende mannen. Ondanks haar nieuwe heel aantrekkelijke uiterlijk is PJ blijven hangen aan haar "symptoom" wat haar fysieke gezondheid en seksueel leven drastisch heeft verstoord en haar emotionaliteit heeft verwoest.

De gehandicapte Fransje is in tegenstelling tot de dynamische en levendige Joe, levenslang veroordeeld tot zijn rolstoel. Sterker nog, hij kan niet goed articuleren en maakt daardoor dag in dag uit gebruik van notities. Een drempelmoment is voor hem als hij opeens te weten komt dat zijn vader tegen hem heeft gelogen. Fransjes vader heeft hem de opdracht gegeven briketten te persen in de achtertuin. Volgens hem bestaat er vraag naar dergelijke briketten het dorp. Fransje is min of meer blij met zijn werk omdat hij zich voor het eerst als een volwaardig lid van de dorpsgemeenschap voelt. Tijdens een toevallig bezoek aan de sloperij van zijn vader ziet Fransje echter de gestapelde briketten. Hij begrijpt dat alles geënsceneerd was en dat zijn inspanningen eigenlijk zinloos zijn geweest. Het inzicht dat de identiteit gecreëerd door zijn ouders eigenlijk vals was, betekent voor Fransje het einde van de illusie: - "ik zag mijn eigen schaamte weerspiegeld in zijn ogen, en zo stonden we elkaar aan te gapen in die Spiegelzaal van Pijnlijkheden" (Wieringa 2005: 197). Hij is daarna niet langer het "symptoom" van zijn ouders, leeft vrij van leugens en kiest er zelfverzekerd voor om armworstelaar te worden.

\subsection{Caesarion - oedipuscomplex en thuisloosheid}

Dat het subject ook klem kan blijven zitten in de oedipale fase bewijst het leven van Ludwig en zijn moeder Marthe Unger in de roman Caesarion. Het oedipuscomplex houdt in dat het jongetje seksuele verlangens koestert ten opzichte van de moeder en de vader als rivaal ervaart. Lacan ziet het einde van deze moeder-zoonrelatie in de rol van de vader, een gegeven dat hij in het kader van de maatschappij en zijn autoriteiten Naam-van-de-Vader noemt. In Caesarion staan de symbolische vadermoord en de gesublimeerde seks met de moeder centraal.

Vroeg verlaten door zijn vader - groeit Ludwig alleen op met zijn moeder. Sterker nog, hij is van haar niet te scheiden. Zo laat hij zich zelfs door haar schminken en geniet daarbij van de intieme nabijheid. "Ik hield van de bedwelmende zoetheid van haar slaapkamer, de warmte van haar lichaam vlak bij de mijne. Het wond me op. Soms masturbeerde ik nadien" (Wieringa 2009: 71). Tijdens de adolescentie komt Ludwig plotseling van een medeleerling te weten dat zijn moeder een wereldberoemde pornoactrice is geweest. Pas dan gaat hij de werking van de "Naam-van-de-Vader" voelen en doet hij bewust moeite zijn mannelijke identiteit te ontdekken en te handhaven en een mannelijke seksualiteit te ontwikkelen.

Het verhaal van Caesarion speelt zich af op vier continenten. Ludwig en zijn moeder verhuizen vaak, maar ook Ludwig zelf kan zich helemaal niet settelen. "Ludwig Unger, de hoofdpersoon van Caesarion, is een Oedipus die een odyssee onderneemt" (Van Rooij 2009: 2). Ludwigs reizen over de hele wereld worden gedreven door de zoektocht naar zijn vader en het beschermen van zijn moeder - "Ludwig wordt strategisch heen en weer geslingerd tussen zijn dominante moeder en (zijn voorstelling van) zijn afwezige vader. Zijn wereld wordt gedomineerd door zijn absente vaderfiguur en de problematische moederbinding" (Van Rooij 2009: 8). Tot aan de dood van de moeder en de directe confrontatie met de vader blijft hij op deze manier fundamenteel afhankelijk van zijn ouders - 
"Zijn moeder blijft het object van zijn lusten en zijn vader blijft de grote afwezige, tot de ontknoping" (Van Rooij 2009: 11).

Ludwig heeft letterlijk geen thuis. Het huis waar hij de langste tijd met zijn moeder heeft gewoond, stort na een heftige storm de zee in. Zijn vader is afwezig en daardoor krijgt hij alleen van zijn moeder liefde, een liefde die zich tot beklemmende warmte en een uiterst manipulatieve binding vervormt. Ludwig heeft niet alleen fysiek geen thuis. Door zijn ongezonde en problematische relatie met zijn ouders ontbreekt het hem aan een thuisgevoel, aan de juiste geborgenheid en aan innerlijke stabiliteit. Tijdens zijn verblijf in Los Angeles ontmoet hij een jonge vrouw en begint met haar een gepassioneerde verkering, maar hij laat haar later in de steek omdat hij dicht bij zijn moeder wil blijven en haar graag wil begeleiden. Vanwege zijn enorme identificatie met en zijn afhankelijkheid van zijn moeder blijkt hij niet in staat tot een echte liefdesrelatie. Een paar jaar later heeft Ludwig nog steeds geen vaste baan of vriendin. Ludwig is voortdurend op reis en kiest vooral voor exotische badplaatsen, waar hij officieel als barpianist werkt, maar eigenlijk een volstrekte mannelijke kopie van zijn moeder is, namelijk een gigolo die slaapt met allerlei oudere welgestelde vrouwen. Daarbij spelen gevoelens, het geweten of spijt helemaal geen rol en krijgen zijn oedipale fantasieën een verwrongen vorm - "Ik was in die jaren de minnaar van echtgenotes, weduwen, vrouwen die zeiden Ik ben oud genoeg om je moeder te kunnen zijn. Hiertoe spoorde ik ze aan, zich over mij te ontfermen, mij te voeden en te kleden, mijn moeder te zijn" (Wieringa 2009: 275).

De jongeman probeert zijn kwetsbaarheden in de wijde wereld te ontvluchten, maar eigenlijk is hij wanhopig op zoek naar liefde, wortels en houvast.

In een interview voor Trouw zegt Tommy Wieringa zelf over Ludwig:

"Neem de geschiedenis van Ludwig. Het was een mooie ontdekking voor me dat die jongen zo naar binding streeft. Hij zoekt naar begrip en eenwording. Hij wil een huis. Hij wil thuiskomen. Die doelen streeft hij trouw na, met bijna masochistische volharding. Terwijl ik rekende op een geperverteerd monster." (Blom 2009: 15)

De laatste zin van de roman "Ik was alleen. En alles begon." (Wieringa 2009: 366) laat zien dat Ludwig, nu hij onafhankelijk is, eindelijk een leven voor zichzelf kan beginnen. Hij hoeft zich niet langer met zijn ouders te identificeren, verantwoordelijkheid voor hen te nemen en hun fouten steeds weer te herhalen. Hij begint opnieuw en lijkt voortaan vrij in zijn doen en laten.

\subsection{Dit zijn de namen - God en zondebok}

Eén van de hoofdpersonages in Dit zijn de namen is de weemoedige en eenzame politiecommissaris Pontus Beg. Hij is van middelbare leeftijd en woont in Michailopol, een fictieve stad in de Oekraïne. Beg bekeert zich tot het jodendom nadat hij opeens aanwijzingen heeft gevonden dat zijn moeder van joodse afkomst is. Ondanks zijn leeftijd is het hem nog niet gelukt een gezin te stichten, hij is een gecorrumpeerde, ziekelijke en norse man geworden. Het gebrek aan samenhorigheidsgevoel en aan erkenning en respect door de anderen probeert hij te compenseren door zijn nieuwe joodse identiteit. Zo bijvoorbeeld, aan het einde van het verhaal, stelt hij aan een vluchtelingsjongen voor, hem te adopteren om hem de joodse identiteit te kunnen geven. Als één van de "uitver- 
korenen" hoeft Beg, met zijn nieuwe, maar onechte zelfverzekerdheid, zich met oude pijn en nieuwe emotionele trauma's niet te bemoeien.

"Zelfs van het vuil dat er niet afging, zou hij zich schoonwassen. Een nieuwe ziel. Daar diep in de aarde, bij het magische water, leek zoiets werkelijk mogelijk. Zijn oude ziel afleggen, dat rafelige versleten ding, er een nieuwe voor in de plaats krijgen. Wie wilde dat niet?" (Wieringa 2013: 130)

De tweede verhaallijn gaat over een groep naamloze vluchtelingen die ergens in de Oekraïne een gevaarlijke reis beginnen. Ze verlangen naar een beter leven in het "beloofde land" ergens in het westen. Omdat een bende oplichters een nepgrens maakt, zijn ze genoodzaakt, door de steppe te dwalen tot ze uiteindelijk uitgehongerd in de stad Michailopol belanden. Egoïsme, gewelddadigheid en wanhoop domineren de stemming tijdens de tocht. De spanning escaleert als de groep één van de medereizgers vermoordt, namelijk een zwarte man uit Ethiopië. Hem worden eerst boze toverkrachten toegeschreven maar na zijn dood nemen de anderen zijn hoofd mee en beginnen ze te geloven dat de geest van de Ethiopiër hen op een geheimzinnige en bovennatuurlijke manier in de goede richting leidt.

Interessant in dit opzicht is de theorie van de antropoloog, filosoof en literatuurwetenschapper René Girard over de zondenbok en het slachtoffermechanisme. Volgens hem ligt de zondenbok aan de grondslag van de menselijke cultuur. In een liminale situatie met een neerwaartse spiraal van escalerende conflicten en geweld is er slechts één mogelijke oplossing - een volstrekt onschuldige moet voor schuldig worden verklaard en vervolgens buitengesloten en vermoord. Dit komt overeen met de stelling van de Franse literaire criticus en filosoof Jacques Derrida over de zondenbok.

"The ceremony of the pharmakos [the scapegoat] is thus played out on the boundary line between inside and outside [of the city.] [...] The origin of difference and division, the pharmakos represents evil both introjected and projected. Beneficial insofar as he cures - and for that, venerated and cared for - harmful insofar as he incarnates the powers of evil - and for that, feared and treated with caution. Alarming and calming. Sacred and accursed." (Plate 2005: 125)

In Dit zijn de namen fungeert de steppe als een oneindige drempel, een eindeloos niets dat het onbewuste en de meest duistere driften naar voren doet komen. Vlak na de dood van de Ethiopiër zijn de gewelddadige instincten van de vluchtelingen getemperd en komen zij inderdaad in aanraking met het culturele. In een aantal interviews geeft Wieringa overigens zelf toe de theorie van Girard in de roman Dit zijn de namen experimenteel te hebben willen testen.

\section{Conclusie}

Elke van deze drie romans van Wieringa geeft een eigen, unieke kijk op de in liminale fases en ruimtes gevormde identiteit. De psychoanalytische en poststructuralistische aanpak helpt ons de samenhang en motieven beter te begrijpen, zoals de redenen na te gaan voor de onoverbrugbaarheid van de drempel. 
Joe Speedboat toont de adolescentie als cruciale drempelperiode. Joe en PJ weigeren, zich van hun zelf verzonnen identiteitskenmerken af te grenzen en blijven daardoor klem zitten in een cirkel van zich herhalende situaties. Joe is de avontuurlijke jongen die nooit kan stilstaan en verantwoordelijkheden ontwijkt, en PJ de schoonheid die mannen alleen maar gebruikt om steeds weer de bevestiging van haar vrouwelijke zelfverzekerdheid en aantrekkelijkheid te krijgen. Fransje slaagt erin zich van de voorstellingen van zijn ouders te distantiëren en zich op zijn eigen interesses en hobby's te concentreren.

De onmogelijkheid van Caesarions Ludwig zijn verboden seksuele drangen en oedipale dromen te vervullen en de schokkende waarheid over het geheimznnige verleden van zijn moeder oefenen een verwoestende invloed uit op zijn seksuele leven als jongvolwassene. De consequenties zijn Ludwigs onvermogen een langdurige liefdesrelatie op te bouwen, zijn innerlijke verscheurdheid tussen zijn ouders en thuisloosheid en zorgeloos zwerversbestaan.

Dit zijn de namen beschrijft een doorsnee man van middelbare leeftijd die met zijn psychologische en emotionele problemen worstelt en hoopt antwoorden in de religie te vinden. De gebeurtenissen tijdens de moeizame en uitzichtsloze tocht van de groep vluchtelingen tonen de menselijke oerinstincten in werking. Deze driften leiden wel tot gruwelijkheden en vernietiging maar uiteindelijk ook tot de verlossing.

\section{BIBLIOGRAFIE}

BLOM, ONNO (2009). 'Ik rekende op een geperverteerd monster'. In: Trouw. 15.05.2009. https://www .trouw.nl/home/-ik-rekende-op-een-geperverteerd-monster- a75853c7/ Geraadpleegd 20.04.2018.

EVANS, DYLAN (1996). An introductory dictionary of Lacanian Psychoanalysis. London: Routledge.

GENNEP, ARNOLD VAN (1960). The Rites of Passage. University of Chicago Press.

KIRSHNER, LEWIS (2011). Between Winnicott and Lacan: A Clinical Engagement. London: Routledge. MOOIJ, ANTOINE (1975). Taal en verlangen. Lacans theorie van de psychoanalyse. Amsterdam \& Meppel: Boom Uitgevers.

NOBUS, DANY (1998). Key concepts of lacanian psychoanalysis. London: Rebus Press.

PLATE, S. BRENT (2005). Walter Benjamin, religion and aesthetics: rethinking religion through the arts. London: Routledge.

ROOIJ, JEROEN VAN (2009). Een mislukte Oedipus in deReactor.org - Platform voor literaire kritiek. 18.10.2009. http://www.dereactor.org/home/detail/een_mislukte_oedipus/Geraadpleegd 20.04.2018.

THOMASSEN, BJORN (2014). Liminality and the Modern. Living Through the In-Between. London: Routledge.

THYS, MICHEL \& MARK KINET (2002). Liefdesverklaringen. Over perversie, liefde en passie. Leuven: Acco.

TURNER, VICTOR (1991). The Ritual Process. Structure and Anti-Structure. Cornell University Press.

VERHAEGHE, PAUL (1998). Liefde in tijden van eenzaamheid. Drie verhandelingen over drift en verlangen. Amersfoort: Acco.

WIERINGA, TOMMY (2005). Joe Speedboot. Amsterdam: De Bezige Bij.

WIERINGA, TOMMY (2009). Caesarion. Amsterdam: De Bezige Bij.

WIERINGA, TOMMY (2013). Dit zijn de namen Amsterdam: De Bezige Bij. 


\section{LIMINALITA A IDENTITA V ROMÁNECH TOMMYHO WIERINGY JOE SPEEDBOAT, CAESARION A DIT ZIJN DE NAMEN}

Tommy Wieringa (1967) je jedním z nejvýznamnějších současných nizozemských spisovatelů. Jeho tři nejslavnější romány - Joe Speedboat, Caesarion a Dit zijn de namen líčí různé aspekty liminální, neboli přechodné identity. Většina protagonistů ovšem není schopna dokončit určitou přechodnou fázi. To má různé důvody, které lze analyzovat pomocí psychoanalytických a poststrukturálních př́ístupů, např́ílad teorií Jacquesa Lacana, Donalda Winnicotta, René Girarda a Jacquese Derridy. Zkušenosti protagonistů odrážejí mnoho z těchto tendencí a zajímavě demonstrují pocit nehybnosti uprostřed mobility.

\section{Sonya Dimitrova}

University of Veliko Turnovo St. Cyril and St. Methodius

E-mail: sonya.m.dimitrova@gmail.com 